\title{
Comparative Approaches to Accessibility Education in the United States and Russia
}

\section{Susan Gallagher, Montana State University}

Susan Gallagher is the Education and Workforce Program Manager at the Western Transportation Institute (WTI), a transportation research center within Montana State University's College of Engineering. Her professional roles include grant writing, program development and management, research, and conducting community and educational outreach. She additionally manages: the West Region Transportation Workforce Center (WRTWC), a resource center serving a ten-state regional network of transportation organizations, workforce advocates, and educational institutions; the Research Experience for Teachers program at MSU on Innovative Transportation Systems; and the National Transportation Safety Career Pathways Initiative.

\section{Prof. Irina Karapetyants, Russian University of Transport}

Dr. Irina Karapetyants serves as the Director of the Institute of International Transport Communications at the Russian University of Transport (RUT). She additionally leads a special Training Resource Center for Accessible Transportation that was established by the Ministry of Transport of the Russian Federation at RUT. Dr. Karapetyants' research interests include international transport systems, innovations in education, international relations in the sphere of transport communications, iternational logistics and supply chain management, sustainable development and ecology.

\section{Mrs. Karalyn Clouser, Western Transportation Institute at Montana State University}

Karalyn Clouser is a GIS and planning specialist with the Western Transportation Institute. She has experience editing and managing spatial data to support transportation planning and implementation projects, and offers skills with numerous GIS tools and platforms. At WTI, she has provided GIS and planning support to the Paul S. Sarbanes Transit in Parks Technical Assistance Center, which assists with the development of alternative transportation on federal lands. Her experience includes developing a route numbering system for the Boise District office of the Bureau of Land Management in Idaho. Ms. Clouser earned her B.S. in Earth Sciences (GIS/Planning) from MSU and is currently working on her Master of Sustainable Transportation at UW.

\section{Dr. Natalie Marie Villwock-Witte P.E., Western Transportation Institute at Montana State University}

Dr. Natalie Villwock-Witte is an Assistant Research Professor/Research Engineer at the Western Transportation Institute at Montana State University. She has more than fourteen years of experience from both the practitioner and research side of transportation engineering. In addition, Natalie is a registered engineer in the state of New Mexico. Natalie has taught a short-term study abroad course through Montana State University and an introduction to engineering education course at the Central New Mexico Community College. 


\title{
Comparative Approaches to Accessibility Education in the United States and Russia
}

\begin{abstract}
Differences in national contexts have led to uneven global development of transportation systems that are accessible to people with disabilities. The World Health Organization promotes the worldwide implementation of education and professional training programs to foster a mindset supportive of accessibility [1]. The education of future engineers is an essential component in this process.

Engineering degree programs are often challenged to cover fundamentals, leaving little time for students to pursue elective coursework or for faculty to integrate consideration of major global societal challenges into existing courses. Pedagogical approaches to content delivery also vary. Many programs focus exclusively on regulatory-based standards, while some programs seek to foster student empathy to improve user-centered design [2]. This paper presents the results of research conducted jointly by two transportation engineering institutions, located in the Russian Federation and the United States respectively, to compare delivery approaches and content in degree-granting transportation curricula on the topic of accessibility. The purpose of the international collaboration was to identify promising practices for enhancing education efforts aimed at building a culture of accessibility for engineering professionals within two distinct national contexts.

Data collection was undertaken to better understand current practice, shortcomings, and successful strategies in accessibility education in Russia and the United States. Project partners conducted national scans of available curricula in their respective countries. The paper presents survey data on course content related to accessibility from eighty-five institutions of higher education in the United States offering transportation programs of study. The Russian institution's national scan found little existing coursework on accessible transportation; the paper therefore presents information about the institution's development of new degree-level coursework on accessibility to be implemented at education institutions nationwide. The information exchange and comparative analysis of approaches to accessibility education in the Russian Federation and the United States help to identify potential avenues for the application of successful education strategies to promote awareness of accessibility issues and to prepare engineering students for professional practice.
\end{abstract}

\section{Introduction}

Freedom of movement is identified as a human right within the Universal Declaration of Human Rights. Public transportation system planning decisions, vehicle and infrastructure design, communication practices, and passenger services all impact individuals' access to mobility. This is particularly true for persons with disabilities, who frequently cite inadequate transportation access as a limiting factor in their desired levels of mobility [3], [4]. Awareness and sensitivity to 
disability rights are key components in fostering accessibility. The European Commission advocates for accessibility courses to be taught at all educational levels [5]. In the transportation field, universities play a major role in developing future professionals by providing them with the foundational knowledge, skills, abilities, and attitudes that will guide their decision-making processes once in the workforce. However, it is unclear how accessibility topics are currently integrated into university programs that act as feeders to the transportation workforce.

Following the Russian Federation's ratification of the UN Convention on the Rights of Persons with Disabilities in 2012, a national survey of Russian citizens with disabilities was conducted to identify priority issues. Over $60 \%$ of survey respondents indicated that "lack of specially trained personnel” was a limiting factor for accessing transportation [6]. To address this need, the Training Resource Center for Accessible Transportation was established by the Ministry of Transport at the Moscow State University for Transport Engineering (MIIT) in 2015. The goal of the Center was to develop training and education resources, methodologies, and expertise to improve the accessibility of public transportation systems and facilities.

A collaborative international project was initiated between MIIT and the Western Transportation Institute (WTI) at Montana State University with the purpose of sharing information and resources on accessibility training and education curricula and methodologies. The joint project was funded by the Eurasia Foundation's University Partnership Program and the Small Urban and Rural Livability Center. Over the course of the project, researchers conducted surveys (in the U.S.) and interviews (in Russia) with university education providers on accessibility content. This paper shares results from respective data collection and curriculum development efforts undertaken by project partners and discusses how different educational approaches can be applied to the common issue of transportation accessibility to better address this global challenge. The international comparison serves to highlight educational gaps and provides food for thought on potential approaches to increasing awareness and sensitivity to transportation accessibility issues for people with disabilities among future transportation professionals.

\section{Methodology: Accessibility Course Content Scan}

The research team was interested in determining the prevalence of accessibility content in postsecondary transportation programs in the United States and Russia. Two different approaches were utilized to gather this information in each respective country. In the United States, a survey was distributed to post-secondary transportation degree programs. The initial survey was distributed to a list of 239 institutions of higher education offering transportation degree programs. The survey distribution list was compiled from transportation program compendiums assembled by a national network of regional transportation workforce centers, and included universities designated as University Transportation Centers (UTCs) by the U.S. Department of Transportation. Degree programs queried included specialized transportation programs (e.g. aviation) as well as civil engineering, construction, and urban and regional planning programs at the Associate’s, Bachelor's, and graduate levels.

Initial responses were predominantly representative of four-year civil engineering degree programs. Civil engineering is a major feeder program for future transportation-focused careers, spanning occupations in roadway and infrastructure design, operations, traffic engineering, 
transportation planning, and transit. To better understand how accessibility is covered in this core discipline, a second round of surveys was sent out to an additional 231 program contacts for ABET accredited civil engineering programs across the United States. After removing incomplete responses as well as four responses from organizations representing professional development rather than degree-granting programs, survey data was analyzed from 85 respondents, with analysis focused primarily on the 68 respondents representing civil engineering graduate and undergraduate degree programs.

The first survey instrument asked, "Does your program offer any courses fully devoted to accessibility issues?” If yes, respondents were asked to list course titles and credit hours. However, no institutions indicated offering a course solely focused on accessibility. To obtain better information on courses offering accessibility content, the second survey instrument was changed to ask, "Does your department offer course content related to the Americans with Disabilities Act (ADA) and accessibility?” and to request course title and credit hour information on all departmental courses offering accessibility content. A search was then conducted to locate course information and syllabi for listed courses. Ten course syllabi, representative of courses at eight different universities, were obtained from civil engineering courses listed in the survey as containing content related to the Americans with Disabilities Act (ADA) or accessibility. The syllabi were reviewed for content and course materials related to accessibility.

The methodology utilized in Russia for gathering information on accessibility course content was different. MIIT is the country's leading state institution of higher education in transportation, encompassing branch campuses in 22 regions of the Russian Federation. As the lead transport institution, MIIT conducted outreach to faculty at the 18 regional universities offering 5-year specialist degree programs in transportation (the equivalent of a 5-year combined Bachelor's/Master's program in the U.S.). Multimodal specialty degrees include: transportation operations, management, logistics, transportation technologies, and traffic safety. These institutions fall under the joint administrative oversight of both the Ministry of Education and the Ministry of Transport. Informal interviews with transportation faculty at regional campuses were employed to gather information on what, if any, accessibility content was currently being offered in transportation specialty degree programs.

\section{Findings - Russia}

Accessibility content coverage for transportation programs at Russian universities was found to be sparse with no clear content requirements in place. As a result, a major task for the MIIT Training Resource Center became to develop and implement a structured curriculum on accessibility for pre-career university transportation students. In executing this task, the Center also developed a training course for faculty to enable them to teach accessibility as a topic. The faculty training course was initially piloted with three different faculty groups representing higher education institutions from the Far East of Russia to the Western portion of the country. Seventy faculty members participated in all.

The accessibility course developed for university students outlines content covering 72 academic hours, divided between lectures (18 hours), practical sessions/seminars (36 hours), and independent study (18 hours). The university course, titled "Development of an Accessible 
Transportation Environment for People with Disabilities," was approved by the Ministry of Transport as well as by disability rights advocacy groups and the Ministry for Social Protection. The stated educational goal for the course is to develop competencies (knowledge, skills, and abilities) which will enable the graduate to work successfully in providing services for people with disabilities and those with limited mobility on transport.

Course learning objectives include:

- $\quad$ To form a basic understanding of the regulatory and legal framework establishing accessibility requirements for transportation facilities and services and the ability to implement them in accordance with provisions of the UN Convention on the Rights of Persons with Disabilities, signed by the Russian Federation in 2012;

- $\quad$ To develop knowledge of specialized systems, technologies, facility features, and services that foster accessibility; and

- $\quad$ To develop practical skills in providing situational assistance to people with disabilities.

Competency areas are focused in two primary areas, as described in more detail below.

Competency Content Area 1: Understand the needs of persons with disabilities, different means of communication, and methods of providing assistance, including through the use of specialized equipment or technologies.

Description: Understanding different service needs involves first understanding different types of disability, including hidden disabilities, to determine what is needed to overcome mobility barriers. Students are expected to gain competencies in identifying and assessing the physical, information, and communication needs of persons with disabilities in both standard and emergency situations and to know different techniques for providing situational assistance on transport to people with different disabilities. Reading materials for this portion of the course include the International Classification of Functioning, Disability and Health (ICF) [7]. The competency area contains an ethics component, which focuses on proper communications etiquette as well as awareness and tolerance for physical, social, ethnic, and cultural differences. The practical portion includes a section on basic sign language.

Competency Content Area 2: Understand the interaction of different contributors to the creation of an accessible transportation environment - system components, organizational roles, legislation and public policies - and the role each plays in supporting barrier-free mobility.

Description: Students are expected to understand current legislation and regulations establishing accessibility standards for transportation infrastructure/facilities and passenger services, including liability issues for transportation agencies. The role executive oversight authorities, transport companies, and disability rights organizations play in ensuring an accessible transportation environment is covered as well as the different functional responsibilities of transportation agency staff in terms of ensuring accessibility and providing services. Content includes information on performance indicators for assessing accessibility of facilities and services. Course readings include theoretical material on the application of the principles of "universal design" and "reasonable accommodation." 
The first two years of most specialized five-year transportation programs of study contain a full load of mandatory coursework. Recognizing this, the accessibility course was originally designed as an elective course to be taken during a student's third year of study. However, acknowledging the importance of developing transport students' competence regarding implementation of accessibility standards, the course became mandatory beginning with the 2017-2018 academic year for students pursuing specialist degrees at the 18 transport institutions of higher education in the Russian Federation. A textbook has also been developed, which will be released in Spring 2019.

\section{Findings - United States}

The higher education system for transportation-related degree programs in the United States is less centralized, less vocationally focused, and does not contain an analogous mechanism to implement a standardized course curriculum across all institutions. The research team therefore opted to undertake a broad national survey to get a better sense of the extent and thematic content of accessibility coursework currently taught at colleges and universities in the United States.

Fifty-four responses were received from the initial survey distribution effort to colleges and universities offering multidisciplinary transportation degree programs at different levels (Associate's, Bachelor's, and Master's/PhD). Seven responses were removed from the data analysis either because they presented incomplete information or because they represented professional development training programs for incumbent transportation workers rather than degree programs. Seven respondents represented two-year community/technical colleges and degree programs. The remaining forty represented four-year universities, with only three respondents from departments outside of engineering.

The second survey distribution targeted ABET accredited civil engineering programs. A total of 38 responses were received. Four responses were received from non-engineering departments and 31 respondents represented civil engineering departments at four-year institutions.

Two-Year Degree Programs with a Transportation Focus $(n=7)$

Seven survey responses were received from two-year community or technical colleges. The sample size is too small to draw any conclusions, but a summary is provided for comparison purposes. Two respondents were unsure whether their institution offered course content related to the ADA or accessibility. Five indicated that their institutions did provide this content, but only two provided any further detail—an Associate's degree program in architecture and an Associate's/Certificate program in Computer Aided Design Drafting (CADD). Not surprisingly, both programs indicated that the topic focus area for ADA content was on infrastructure and universal design. For both programs, the content was integrated into required coursework. One respondent estimated that students would devote 4 to 14 hours to ADA/accessibility considerations while completing their Associate's degree, while the second program estimated 15 to 42 hours would be devoted to the topic. 
Four-year Non-Engineering Degree Programs ( $n=7)$

Only seven responses from four-year non-engineering degree programs were received. The sample size is again too small to draw any conclusions, but a summary of responses is provided. Responding departments included: planning or urban planning (3); architecture (1); landscape architecture (1); as well as two specialized transportation programs in aviation (1) and transportation and logistics (1). All seven reported offering ADA/accessibility content in department coursework with 3 respondents reporting the content as part of a required course. Three respondents estimated that students at the Bachelor's degree level would devote approximately 1 to 3 hours to ADA/accessibility considerations while completing their degree; and three respondents estimated students at the graduate (Master's/PhD) level would devote approximately 4 to 14 hours to accessibility topics during their degree completion. Content coverage areas were fairly comprehensive, as shown in Figure 1, with public policy/social sciences content receiving the most attention, followed by legal compliance and infrastructure/universal design topics.

\section{Accessibility-Related Content Coverage Areas for Non-Engineering Degree Programs}

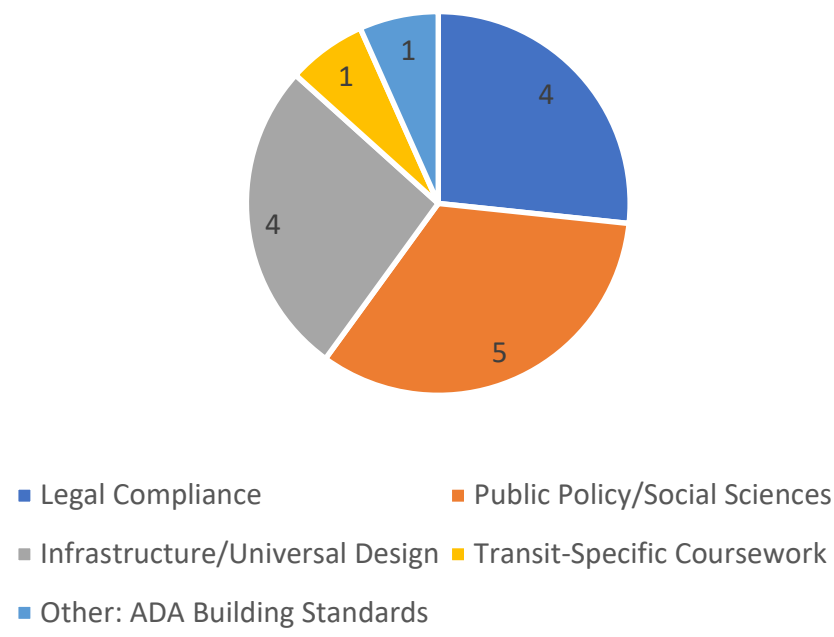

Figure 1: Thematic areas for accessibility content in non-engineering degree programs

Four-Year Engineering Degree Programs ( $n=71)$

Responses from 71 engineering degree programs at universities nationwide were obtained. Responses provided good national geographic coverage, with responses representative of 69 institutions in 35 states and Puerto Rico. Multiple institutions reporting from one state are indicated by the numbers on the map in Figure 2. 


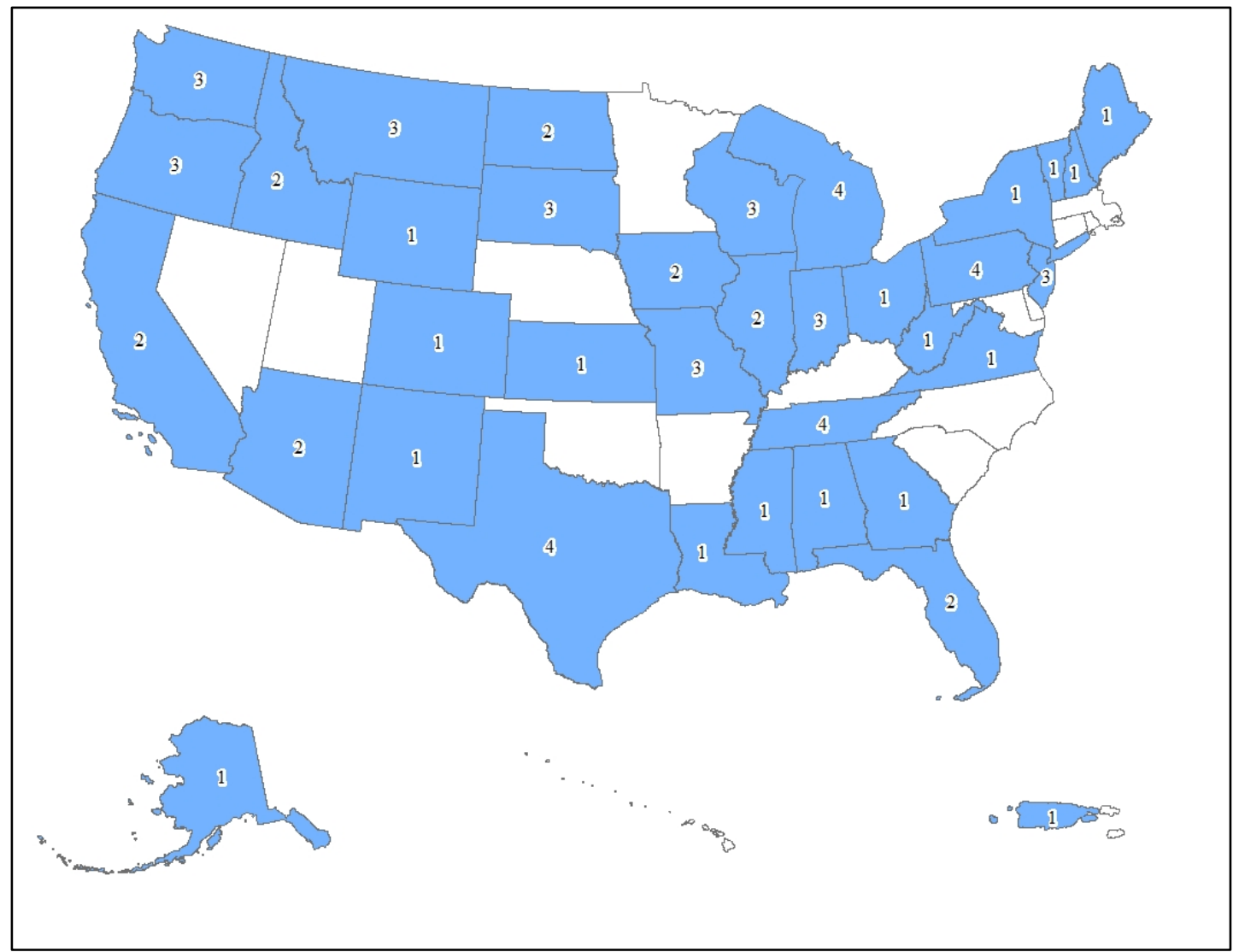

Figure 2: Geographical coverage of survey respondents

Figure 3 displays response rates to the question, "Does your institution offer course content related to the Americans with Disabilities Act (ADA) and accessibility?”

\section{Course Content offered on ADA or Accessibility?}

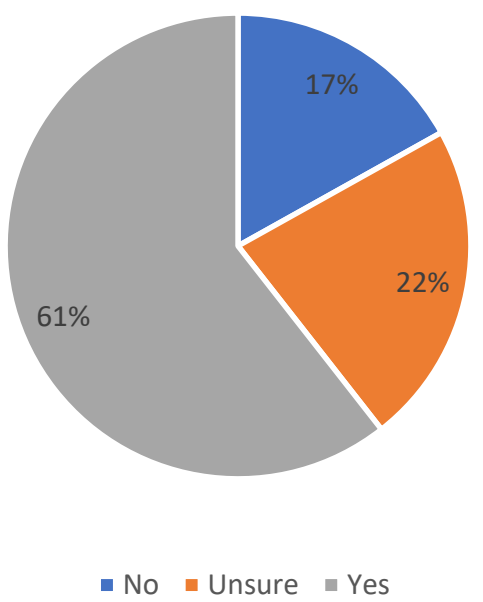

Figure 3: Percentage of university engineering programs offering course content on accessibility 
Sixty-one percent of four-year engineering degree programs reported offering accessibilityrelated course content. Two responses came from larger units representing multiple departments within engineering (e.g. a college of engineering) and one response was from an industrial engineering department. All three indicated that no course content related to the ADA or accessibility were offered by their academic units. Sixty-eight respondents represented civil or civil and environmental engineering departments. Three respondents indicated "yes” regarding accessibility course content but did not provide any additional information. Details offered on accessibility-related course content provided by forty civil engineering degree programs are presented below.

Survey respondents indicating that accessibility content was offered in their programs were asked to select all topic areas the course content covered. The most common topic listed was infrastructure/universal design with 31 out of 40 programs (78\%) offering content in this area. Forty-three percent of the programs offered transit-focused accessibility content and $35 \%$ offered content related to legal compliance. Less prevalent topics included public policy and vehicle design. Only 8 respondents reported offering public policy/social science related accessibility content and 5 responding programs covered vehicle design. Five respondents selected "other" and added text descriptions, which included: traffic safety, traffic flow, transportation, vehicle routing and scheduling, accessibility requirements for public spaces, and civil project design.

Nineteen institutions reported offering accessibility content at the undergraduate level only and three institutions at the graduate level only. Eighteen institutions indicated they offered this content at both the undergraduate and graduate levels. Degree programs were fairly evenly split in terms of whether accessibility content was offered in elective or required courses or both, as shown in Figure 4.

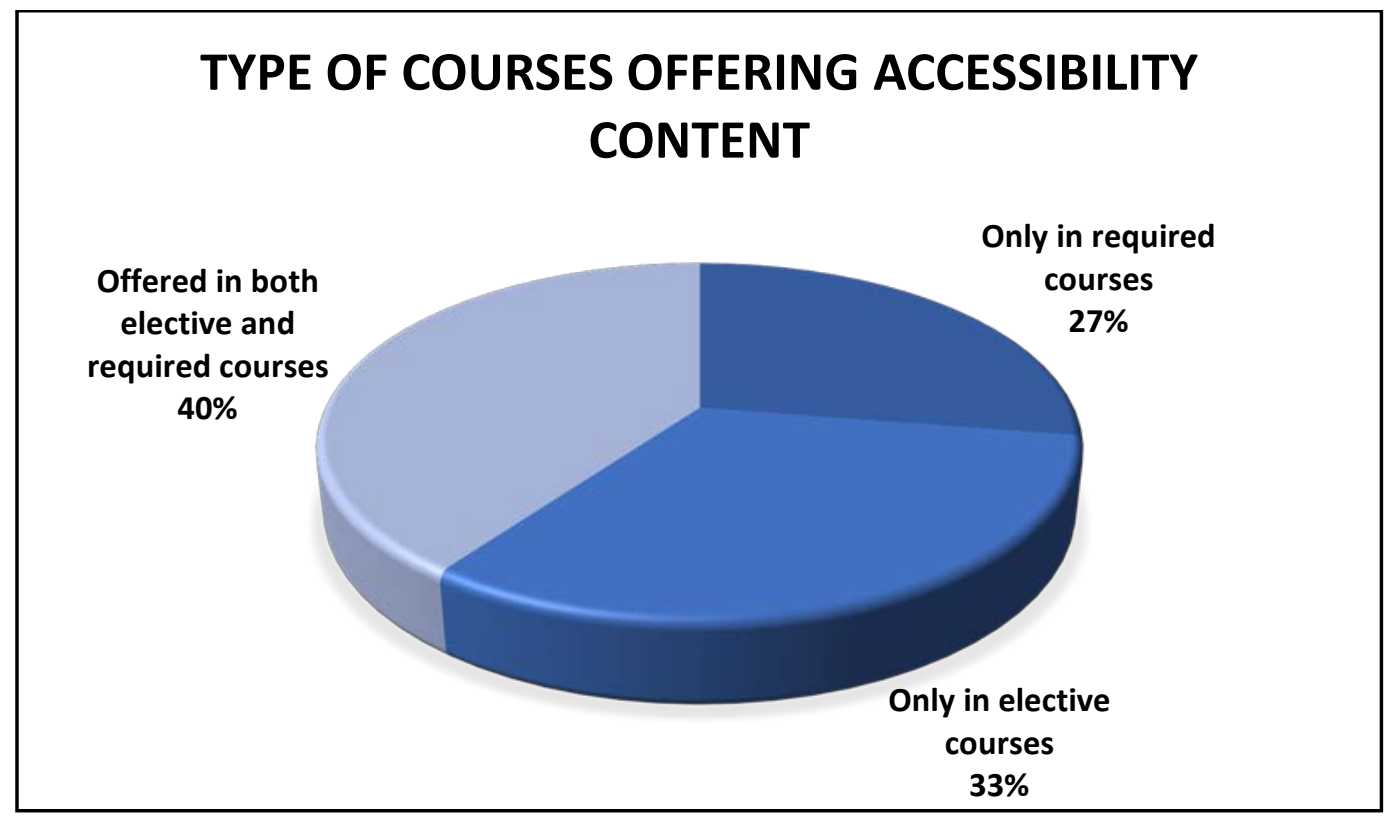

Figure 4: Type of course offering accessibility content 
Respondents were asked "How many contact hours will a student in your program devote to ADA/accessibility considerations while completing a degree?” Of the thirty-seven institutions reportedly offering accessibility content at the Bachelor's degree level, the majority (65\%) estimated that students spend between 1 and 3 class contact hours on the topic. Ten institutions (27\%) estimated students spend between 4 and 14 hours on accessibility topics during degree completion. Only two respondents expected students to spend more than 14 contact hours on the topic at the undergraduate level.

Similarly, 63\% of the twenty-one institutions reporting graduate (Master's and $\mathrm{PhD}$ ) level accessibility content expected students to devote between 1 and 3 class contact hours on the topic. Five institutions (24\%) estimated between 4 and 14 student contact hours on the topic and only two respondents expected students to spend more than 14 hours on accessibility topics at the graduate level. Overall, few differences were observed between the undergraduate and graduate levels in expected student coursework exposure to accessibility topics.

The survey requested information on the course number and title for departmental courses offering content related to accessibility and/or the ADA. Twelve civil engineering programs entered course information for 23 different courses containing ADA/accessibility content. Researchers located online course descriptions for twenty-two of the courses and obtained syllabi for ten of the courses. Course syllabi were obtained for four required introductory transportation engineering courses for civil engineering majors; five upper level or graduate transportationfocused elective courses; and one course focused on facilities construction, maintenance and operation. Syllabi contained information on course reading material/textbooks for 9 courses. Commonly identified course reading materials were reviewed for accessibility content. A summary of course information obtained is provided in Table 1.

Table 1: Information for Courses Listed as Providing Accessibility/ADA Content

\begin{tabular}{|c|c|c|c|c|c|c|c|c|}
\hline Course Title & 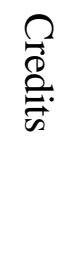 & 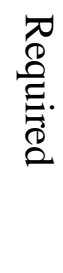 & 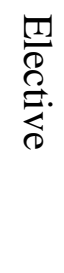 & 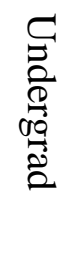 & $\begin{array}{l}\text { Q } \\
\stackrel{0}{0} \\
\stackrel{0}{0}\end{array}$ & 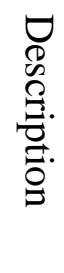 & 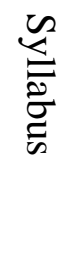 & 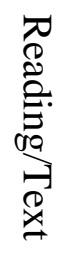 \\
\hline Transportation Engineering & 3 & $\mathrm{X}$ & & $\mathrm{X}$ & & $\mathrm{X}$ & $\mathrm{X}$ & $\mathrm{X}$ \\
\hline Sustainable Transportation Systems \& Policy & 3 & & $\mathrm{X}$ & $\mathrm{X}$ & $\mathrm{X}$ & $\mathrm{X}$ & $\mathrm{X}$ & \\
\hline Transportation Systems Engineering & 3 & $\mathrm{X}$ & & $\mathrm{X}$ & & $\mathrm{X}$ & & \\
\hline Traffic Engineering & 3 & & $\mathrm{X}$ & $\mathrm{X}$ & $\mathrm{X}$ & $\mathrm{X}$ & $\mathrm{X}$ & $\mathrm{X}$ \\
\hline Civil Engineering Project & 3 & & $\mathrm{X}$ & $\mathrm{X}$ & & $\mathrm{X}$ & & \\
\hline Introduction to Transportation Engineering & 3 & & $\mathrm{X}$ & $\mathrm{X}$ & & $\mathrm{X}$ & $\mathrm{X}$ & $\mathrm{X}$ \\
\hline Public Mass Transportation & 3 & & $\mathrm{X}$ & & $\mathrm{X}$ & $\mathrm{X}$ & & \\
\hline Transportation Engineering & 3 & $\mathrm{X}$ & & $\mathrm{X}$ & & $\mathrm{X}$ & & \\
\hline Highway Geometric Design & 3 & & $\mathrm{X}$ & $\mathrm{X}$ & & $\mathrm{X}$ & & \\
\hline Construction Law Management & 3 & & $\mathrm{X}$ & & $\mathrm{X}$ & & & \\
\hline Principles of Transportation Engineering & 3 & $\mathrm{X}$ & & $\mathrm{X}$ & & $\mathrm{X}$ & & \\
\hline Project Design \& Management in CE & 3 & $X$ & & $\mathrm{X}$ & & $\mathrm{X}$ & & \\
\hline
\end{tabular}




\begin{tabular}{|c|c|c|c|c|c|c|c|c|}
\hline Course Title & 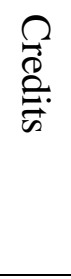 & 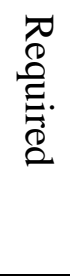 & $\begin{array}{l}\frac{T}{D} \\
\stackrel{2}{\partial} . \\
\stackrel{D}{D}\end{array}$ & 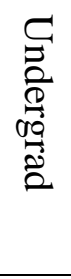 & 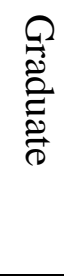 & 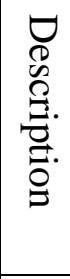 & 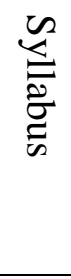 & 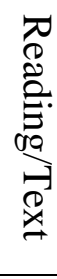 \\
\hline Design of Transportation Systems & 3 & & $\mathrm{X}$ & $\mathrm{X}$ & & $\mathrm{X}$ & & \\
\hline Highway Planning and Design & 3 & & $\mathrm{X}$ & $\mathrm{X}$ & & $\mathrm{X}$ & $\mathrm{X}$ & $\mathrm{X}$ \\
\hline Traffic Characteristics \& Design & 3 & & $\mathrm{X}$ & $\mathrm{X}$ & & $\mathrm{X}$ & $\mathrm{X}$ & $\mathrm{X}$ \\
\hline Mass Transportation Systems & 3 & & $\mathrm{X}$ & & $\mathrm{X}$ & $\mathrm{X}$ & $\mathrm{X}$ & $\mathrm{X}$ \\
\hline Senior Design & 3 & $\mathrm{X}$ & & $\mathrm{X}$ & & $\mathrm{X}$ & & \\
\hline Fundamentals of Building Systems & 3 & $\mathrm{X}$ & & $\mathrm{X}$ & & $\mathrm{X}$ & $\mathrm{X}$ & $\mathrm{X}$ \\
\hline Design of Transportation Facilities & 3 & $\mathrm{X}$ & & $\mathrm{X}$ & & $\mathrm{X}$ & & \\
\hline Urban Transportation Planning & 3 & & $\mathrm{X}$ & $\mathrm{X}$ & & $\mathrm{X}$ & & \\
\hline Transportation Engineering & 3 & $\mathrm{X}$ & & $\mathrm{X}$ & & $\mathrm{X}$ & $\mathrm{X}$ & $\mathrm{X}$ \\
\hline Highway and Traffic Engineering & 3 & $\mathrm{X}$ & & $\mathrm{X}$ & & $\mathrm{X}$ & $\mathrm{X}$ & $\mathrm{X}$ \\
\hline Transportation Infrastructure Design & 3 & $\mathrm{X}$ & & $\mathrm{X}$ & & $\mathrm{X}$ & & \\
\hline Totals: & & 11 & 12 & 20 & 5 & 22 & 10 & 9 \\
\hline
\end{tabular}

Course descriptions were located on institutional or course websites for listed courses. The descriptions provided a high-level overview of course content. None of the course descriptions explicitly call out "accessibility," "accessible transportation," or the ADA. One description indicated content on mass transit passenger characteristics and paratransit systems. Nine other course descriptions alluded to system user characteristics, design standards, or social impacts of transportation system design, which could relate to transportation accessibility for people with disabilities. These include mention of the following topics:

- Road user characteristics or traits and behaviors of road users;

- Applications of national design standards and criteria for geometric design of highways and streets;

- Concepts of livability in transportation system design;

- Human comfort aspect of building utilization;

- Social justice and public health impacts of transportation systems; and

- Social aspects of transportation system improvements.

Only two of the course syllabi obtained explicitly identify ADA or accessibility content. One lists a lecture on paratransit systems in the course schedule and the second clearly lists student learning outcomes to include an understanding of recommended sidewalk widths, ADA requirements for handicapped ramp placement and dimensions, and wheelchair accommodation at intersections.

Course reading materials overlapped for several of the courses, especially in the use of standard design guidance for roadway design and evaluation. The Manual on Uniform Traffic Control Devices (MUTCD) was listed on two course syllabi, the AASHTO Green Book: Policy on Geometric Design of Highways and Streets on three, and the Highway Capacity Manual (HCM) on four. The MUTCD includes a section on accessibility considerations, and provides ADA accessibility guidelines related to crosswalk markings, pedestrian islands and medians, lateral 
offsets for traffic signal supports and cabinets, accessible pedestrian signals and detectors, and devices for pathway grade crossings [8]. The AASHTO Green Book includes a chapter on design criteria, which contains a brief overview of characteristics of persons with disabilities and design accommodations for mobility impairments, visual impairments, and developmental impairments [9]. The Highway Capacity Manual provides an approach for analyzing transportation system components in terms of capacity and service levels and includes information on applications to accessibility and pedestrian facility design [10].

\section{Discussion}

The survey and course syllabi review provide only a high-level snapshot of how accessibility topics are currently covered in civil engineering programs in the United States. Syllabi for several of the project design courses could not be obtained, and regardless, syllabus review may be inadequate for gaining insight into problem-based or design course content since content may vary each semester depending on the client or issue presented for consideration to students. Greater depth of understanding on content and pedagogical approach utilized for introducing accessibility-related topics could be obtained through the addition of qualitative interview data with individual faculty, which constitutes a fruitful avenue for future research.

Nevertheless, some generalizations can be made based on the data at hand. First, there is no evidence of stand-alone civil engineering courses being offered on accessibility. A scan of university-level information and communication technology programs similarly found an absence of separate courses dedicated to accessibility, which the authors concluded indicated a lack of faculty interest, student interest, or perceived need for expertise on the topic [11]. Given the amount of coursework required in typical civil engineering undergraduate programs, the absence of individual courses is not surprising. Both students and faculty are often resistant to appending additional curricular requirements to an already heavy course burden [12]. Rather than segregating content that focuses on the human side of engineering - to include content on social context, user considerations, ethics and inclusivity-into stand-alone courses, there are good arguments to be made for integrating these topics throughout the curriculum [2]. Lack of separate coursework does not equate to lack of curricular content, and integration of the topic into different transportation engineering, design, and construction courses could provide excellent learning opportunities for students on how to apply accessibility principles to multiple aspects of civil engineering professional practice.

Unfortunately, this does not appear to be the current situation. Survey results show an astounding $39 \%$ of respondents either do not cover accessibility topics in their programs or were unsure whether the topic was addressed or not. Among institutions covering the topic, over $60 \%$ reported that students at both the undergraduate and graduate levels will spend no more than 3 hours on the topic over the course of their degree completion. The dearth of accessibility content in civil engineering coursework at the university level is problematic for many reasons. First and foremost, civil engineers are responsible for the design and construction of much of the physical infrastructure in society as well as the design and operation of transportation systems. Barriers to mobility and physical barriers in the environment reduce quality of life for people with disabilities and have the unfortunate consequence of reinforcing attitudinal barriers [13]. A 
survey from 2001 found the engineering workforce lacked the competencies to address the legal requirements for accessible design [14]. Without focused attention paid to the topic at the university level, the workforce skill gap will remain, as will the status quo for people with disabilities who will continue to face physical, information, and mobility barriers left unaddressed by unaware engineers and designers [11].

Legal requirements and mandates for incorporating accessible design into facilities and products are a major driver for incorporating accessibility into engineering content [14]. Survey responses echo this motivator. The most common accessibility topic offered related to infrastructure design (78\% of respondents), and 35\% of responding programs offered content on legal compliance. Much of the reading material from listed civil engineering courses contained accessibility content focused primarily on ADA requirements and design standards, particularly for the pedestrian environment (e.g. sidewalks, curbs, pedestrian signals). There was little evidence of content on the social impacts of accessibility and why accessibility is important. Only eight survey respondents listed content related to public policy or social science.

While legal requirements and accessible design standards are important content for civil engineers, coursework focused primarily on regulatory content may have the unintended consequence of undermining student interest in the topic [11]. New approaches to engineering education, supported by the National Academy of Engineering and updated ABET accreditation language, place greater importance on students understanding social context and the social impacts of engineering design [15]. Human-centered design, once primarily the domain of industrial engineering, is increasingly garnering attention from different disciplines across the academy. In human-centered design, designers actively engage with a broad range of stakeholders to better understand and address the constraints and social needs of users across demographic and economic groups. Ideally, designers develop and embed empathy into the problem-solving process and products [15], [2]. Teaching empathy may present a pedagogical challenge to engineering faculty [2] [16], but insight can be gained into successful approaches from academic fields like social work, which treat empathy as a teachable skill and a requisite professional orientation [16].

The accessibility course developed by MIIT provides an interesting model for consideration. It places emphasis on multiple aspects of the problem, beyond regulatory standards and legal compliance. The course includes content on the broader challenge of ensuring disability rights in a global context, with special focus paid to mobility barriers for people with disabilities. In introducing the principles of universal design, the course emphasizes a design approach that reduces the need for adaptation and hence the stigma attached to specialized accommodation [17]. Importantly, the course does not focus solely on the design aspects of transportation engineering. Much attention is paid to passenger service and the future professional role transportation specialists will play as service providers. In focusing on transportation as a service, the course orients students to an awareness of human differences, ethical issues surrounding inclusivity, the importance of interpersonal communication, and professional responsibility. 
Responses to MIIT's survey assessing transportation barriers for people with disabilities clearly indicated that the level and quality of assistance provided by transportation personnel was a significant factor in accessibility [6]. The finding undoubtedly played a role in the service orientation of the accessibility course developed. It also reveals an understanding that attitudinal barriers can be just as detrimental to the establishment of an accessible transportation environment as physical barriers; an aspect that is frequently overlooked in current engineering pedagogy. The approach underlines the importance of extending a human-centered, empathic orientation beyond the product design level and into the realm of systems and services [16].

As the role of transportation organizations - and consequently the role of the transportation workforce-increasingly moves away from traditional design/build mandates toward increasing the efficiency, capacity, and sustainability of existing systems, the conceptualization of transportation as a service will also grow. Mobility as a service and mobility management represent emerging strategies focused on meeting individuals' mobility needs on a customized basis, utilizing information and computer technologies and coordination between multiple service providers [18]. In this environment, accessible design practices among computer and information technology developers will become increasingly important to ensuring barrier-free mobility for persons with disabilities [19]. Transportation specialists will likewise play a larger role in system design, coordination, and communication tasks. Awareness of, and sensitivity toward, the needs and challenges of all system users on the part of the transportation workforce will be critical to ensuring that transportation systems become more, not less, accessible as systems and technologies evolve.

The international comparison of different educational approaches employed in teaching accessibility topics to university transportation students provides ample food for thought. In Russia, a decision was made that since provision of accessible transportation is mandated by law, a structured program was needed to expose all transportation students to accessibility topics through a designated required course. To address the need for course materials and for improving instructor competency in teaching the topic, a faculty training program was developed as well as a detailed course curriculum and textbook. New curricular mandates are unlikely for transportation programs in the less centralized and less vocationally-focused university system found in the United States. Nevertheless, the survey findings should raise concern about whether higher education institutions in the U.S. are graduating successive generations of designers and engineers without awareness of disability rights and accessibility needs. There is evidence that devoting explicit coverage to disability demographics and universal design in coursework can improve students' attitudes and sensitivity toward persons with disabilities [13]. An interesting avenue for future research would be to undertake longitudinal studies of shifts in student attitudes toward disability following the completion of the MIIT accessibility course as compared with attitudinal shifts experienced by students completing primarily embedded and regulatory-focused accessibility content in courses.

The World Health Organization advocates public awareness raising through education programs to overcome prejudices surrounding disability [1]. A professional mindset that supports accessibility is especially important for fields related to the built environment and mobility. To 
enhance content that fosters sensitivity toward disability rights in the United States, transportation programs will likely need to develop new "collaborations of the willing [12]" with faculty in fields that already have pedagogy oriented toward human service, understanding social contexts, and developing empathic understanding of social and individual needs (e.g. social work, occupational therapy, social sciences) [16], [17]. An enhanced pedagogical focus on professional orientation and practice, especially in terms of addressing social needs through the provision of transportation services, may provide a constructive avenue for enhancing crossdisciplinary accessibility content within university transportation programs.

\section{References:}

[1] World Health Organization, “World Report on Disability,” Geneva, 2011.

[2] L. Mitchell and L. Light, “Increasing Student Empathy Through Immersive User Empathy Experiences in First-Year Design Education,” in American Society of Engineering Education: Proceedings from the 2018 Annual Conference, Paper ID \#21092, June 2018.

[3] J.W. Mattson, J. A. Hough, and A. R. Abeson, “Assessing existing and needed community transportation for people with disabilities in North Dakota,” DP-231. Upper Great Plains Transportation Institute, North Dakota State University Fargo, 2010.

[4] A.M. Jette and M. J. Field, The future of disability in America. National Academies Press, 2007.

[5] European Commission, 2010: A Europe Accessible for All, 2003. [Online]. Available: https://www.accessibletourism.org/?i=enat.en.reports.442 [Accessed February 1, 2019].

[6] V.D. Donchenko, Y. Yenin, Y. Kunin, and A. Kolik, "Ensuring transport systems accessibility for persons with disabilities in the Russian Federation” in Transport Research Arena (TRA) 5th Conference: Transport Solutions from Research to Deployment, Paris, 2014.

[7] World Health Organization. International classification of functioning, disability and health: ICF. Geneva: World Health Organization, 2001.

[8] U.S. Department of Transportation Federal Highway Administration, Manual on Uniform Traffic Control Devices (MUTCD), 2012.

[9] American Association of State Highway and Transportation Officials (AASHTO), Green Book: Policy on Geometric Design of Highways and Streets, 2012.

[10] Transportation Research Board (TRB), Highway Capacity Manual (HCM), 2018.

[11] C. Putnam, M. Dahman, E. Rose, J Cheng, and G. Bradford, “Best Practices for Teaching Accessibility in University Classrooms; Cultivating Awareness, Understanding, and Appreciation for Diverse Users.” ACM Transactions on Accessible Computing, Vol. 8, No. 4, Article 13, Mar. 2016. 
[12] C. Traver, J.D. Klein, B. Mikic, A. Akera, S. Shooter, A. Epstein, and D. Gillette, "Fostering Innovation through the Integration of Engineering and Liberal Education," in American Society of Engineering Education: Proceedings from the 2011 Annual Conference, Paper ID \#2011-1233, June 2011.

[13] B. Chang, K. Tremblay, and B. Dunbar, “An Experiential Approach to Teaching Universal Design.” Education. Vol. 121, No. 1, 2000.

[14] R. Erlandson, “Accessible Design Issues and Principles in the Undergraduate Engineering Curriculum,” in American Society of Engineering Education: Proceedings from the 2001 Annual Conference, Session 2525, 2001.

[15] C. Titus, C. Zoltowski, and W. Oakes, "Designing in a Social Context: Situating Design in a Human-Centered, Social World.” in American Society of Engineering Education: Proceedings from the 2011 Annual Conference, Paper ID \#2011-1989, June 2011.

[16] J. Walther, S. Miller, and N. Sochacka, “A Model of Empathy in Engineering as a Core Skill, Practice Orientation, and Professional Way of Being.” Journal of Engineering Education, Vol. 106, No. 1, pp. 123-148. January 2017.

[17] V. Watchorn, H. Larkin, S. Ang and D. Hitch, "Strategies and effectiveness of teaching universal design in a cross-faculty setting," Teaching in Higher Education. 18:5, 477-490, 2013.

[18] National Center for Mobility Management, "Successful Mobility Management Practices for Improving Transportation Services in Small Urban and Rural Areas,” NCHRP 20-65/Task 68; January 2018. [Online]. Available:

http://onlinepubs.trb.org/onlinepubs/nchrp/docs/NCHRP20-65(68)_FR.pdf [Accessed January 3, 2019].

[19] S. Shaheen, A. Stocker, A. Bhattacharyya, "Multimobility and Sharing Economy: Shaping the Future Market Through Policy and Research.” TR Circular E-C210. National Academies of Sciences, Engineering, and Medicine. Washington, DC 2016. 